\title{
Sympathetic and parasympathetic responses to a core disgust video clip as a function of disgust propensity and disgust sensitivity
}

Citation for published version (APA):

de Jong, P. J., van Overveld, M., \& Peters, M. L. (2011). Sympathetic and parasympathetic responses to a core disgust video clip as a function of disgust propensity and disgust sensitivity. Biological Psychology, 88(2-3), 174-179. https://doi.org/10.1016/j.biopsycho.2011.07.009

Document status and date:

Published: 01/01/2011

DOI:

10.1016/j.biopsycho.2011.07.009

Document Version:

Publisher's PDF, also known as Version of record

\section{Document license:}

Taverne

Please check the document version of this publication:

- A submitted manuscript is the version of the article upon submission and before peer-review. There can be important differences between the submitted version and the official published version of record.

People interested in the research are advised to contact the author for the final version of the publication, or visit the DOI to the publisher's website.

- The final author version and the galley proof are versions of the publication after peer review.

- The final published version features the final layout of the paper including the volume, issue and page numbers.

Link to publication

\footnotetext{
General rights rights.

- You may freely distribute the URL identifying the publication in the public portal. please follow below link for the End User Agreement:

www.umlib.nl/taverne-license

Take down policy

If you believe that this document breaches copyright please contact us at:

repository@maastrichtuniversity.nl

providing details and we will investigate your claim.
}

Copyright and moral rights for the publications made accessible in the public portal are retained by the authors and/or other copyright owners and it is a condition of accessing publications that users recognise and abide by the legal requirements associated with these

- Users may download and print one copy of any publication from the public portal for the purpose of private study or research.

- You may not further distribute the material or use it for any profit-making activity or commercial gain

If the publication is distributed under the terms of Article $25 \mathrm{fa}$ of the Dutch Copyright Act, indicated by the "Taverne" license above, 


\title{
Sympathetic and parasympathetic responses to a core disgust video clip as a function of disgust propensity and disgust sensitivity
}

\author{
Peter J. de Jong ${ }^{\mathrm{a}, *}$, Mark van Overveld ${ }^{\mathrm{b}}$, Madelon L. Peters ${ }^{\mathrm{c}}$ \\ a Department of Clinical Psychology, University of Groningen, Grote Kruisstraat 2/1, 9712 TS Groningen, The Netherlands \\ ${ }^{\mathrm{b}}$ Marketing Management, Rotterdam School of Management, Erasmus University Rotterdam, P.O. Box 1738, 3000 DR Rotterdam, The Netherlands \\ ${ }^{c}$ Department of Clinical Psychological Science, P.O. Box 616, 6200 MD Maastricht, The Netherlands
}

\section{A R T I C L E I N F O}

\section{Article history:}

Received 19 October 2010

Accepted 26 July 2011

Available online 17 August 2011

\section{Keywords:}

Disgust

Disgust propensity

Disgust sensitivity

Parasympathetic nervous system

Heart rate variability

\begin{abstract}
A B S T R A C T
It is generally assumed that disgust is accompanied by increased activation of the parasympathetic nervous system (PNS). However, empirical support for the role of PNS in disgust is scarce. This study tested whether (i) activation of the PNS is indeed involved in disgust and (ii) disgust-induced autonomic activation is especially pronounced in individuals with high disgust propensity or enhanced disgust sensitivity. Participants $(N=60)$ viewed a 5 min disgust-inducing video clip. Participants showed increased parasympathetic activity of both the cardiac and the digestive components of the autonomic nervous system (ANS), together with increased sympathetic activation of the cardiac system. ANS responses were independent of subjective disgust and individuals' habitual disgust propensity or sensitivity. Results support the hypothesis that PNS activation is involved in disgust. The absence of a relationship between subjective and physiological indices of disgust indicates that both types of responses reflect independent phenomena.
\end{abstract}

(C) 2011 Elsevier B.V. All rights reserved.

\section{Introduction}

Disgust has long been acknowledged as one of the basic emotions, recognized across cultures and societies with an evolutionary basis but culturally shaped content. However, in comparison with its complementary emotions, it has long been neglected in scientific research (Olatunji and McKay, 2010; Vaitl et al., 2005). This neglect is even more accentuated when it comes to its psychophysiological signature (Vrana, 2010).

It is generally assumed that disgust is accompanied by increased parasympathetic responses (e.g., Levenson, 1992). Consistent with the view that disgust is accompanied by parasympathetic activation of the cardiac system, it has been shown that participants who engaged in facial prototypes of the expression of disgust or were asked to relive a past disgusting experience did not display the cardiac acceleration that was typically found for other negative emotions such as fear (e.g., Ekman et al., 1983). Furthermore, studies using a passive picture viewing approach found that specifically disgust is related to decreased heart rate (HR) (e.g., Stark et al., 2005). The general finding that disgust tends to elicit HR reduction rather than HR increase is often taken to reflect dominance of the parasympathetic branch of the ANS (see e.g., Levenson, 1992).

\footnotetext{
* Corresponding author.

E-mail address: p.j.de.jong@rug.nl (P.J. de Jong).
}

However, for the understanding of the physiological basis of the cardiac deceleration, it is important to register additional vagal indices like heart rate variability (HRV) to test whether the bradycardia indeed reflects enhanced vagal tone rather then sympathetic withdrawal. Since HRV needs a much longer time window than used in the typical picture viewing or facial expression paradigm, this requires a different experimental timing. Therefore, in previous work we used prolonged disgust imagery ( $5 \mathrm{~min}$ ) rather then picture viewing to investigate further whether disgust is indeed characterized by parasympathetic responses (van Overveld et al., 2009). This earlier study showed that elicited feelings (and facial expressions) of disgust were accompanied by changes in digestive as well as cardiac components of the autonomic nervous system (ANS). For the digestive component, increases were observed in saliva production which most likely indicates an increase in parasympathetic activity (Proctor and Carpenter, 2007). For the cardiac component, increases were observed in T-wave amplitude which generally can be taken to indicate sympathetic withdrawal (Kline et al., 1998). There was, however, no evidence for increased parasympathetic activity of the cardiac component of the ANS with HRV remaining unaffected by disgust imagery.

Yet, the absence of parasympathetic cardiac responding might have been the result of the task demands that are evoked by an imagination procedure. Imagery necessitates considerable mental effort and is often associated with cardiac acceleration (e.g., Vrana, 1993). It would, therefore, be important to examine the role of the parasympathetic component of the ANS in the context of 
other types of prolonged disgust elicitors without this potential confound. Germane to this, a recent study on the cardiovascular dynamics in blood phobia included a non-blood disgust-relevant film of 320 s duration. This passive film viewing study, however, did not provide support for a major role of the cardiovascular component of the parasympathetic nervous system in disgust. Neither blood phobics $(N=14)$ nor non blood-fearful controls $(N=17)$ showed enhanced parasympathetic responsivity during the disgust film (Sarlo et al., 2008). However, the film that was used in this latter study concerned a cockroach invasion. Although cockroaches are undoubtedly disgust-relevant animals (e.g., Davey, 1994), the invasion component may have activated threatening cognitions related to unwanted physical contact with disgusting stimuli (de Jong and Muris, 2002). This type of cognitions will logically elicit physiological fear responses preparing for avoidance and/or escape thereby overshadowing the disgust-specific autonomic responding (cf. Vrana, 2009).

Consistent with this, a subsequent study that used a disgusteliciting film without this potential confound (i.e., a chef who vomits into a transparent bowl after the oral intake of raw eggs) did show tentative evidence for disgust-related parasympathetic activation of the cardiac system. Participants in that study $(N=100)$ showed higher HR variability during passive viewing of this core disgust (vomit) clip of approximate 1 min duration, than during baseline (whilst watching a screensaver) (Rohrmann and Hopp, 2008). Moreover, in support of the view that perhaps the HR acceleration found in previous disgust imagery studies (e.g., Vrana, 1993) might have been due to task demands, viewing the clip did not affect HR per se. Thus watching the vomit clip elicited no cardiac acceleration.

The current study was designed to investigate further the alleged involvement of the parasympathetic branch of the ANS in the disgust response. In an attempt to replicate and extend the preliminary evidence for the parasympathetic involvement in the disgust response (Rohrmann and Hopp, 2008), we used a similar passive viewing approach. However, we used a (core) disgust film of longer duration (5 rather than $1 \mathrm{~min}$ ), thereby complying with the recommendations by the Task Force of the European Society of Cardiology and the North American Society of Pacing Electrophysiology (1996) who argued that a reliable assessment of relevant frequency components of HRV requires a measurement duration of at least $2 \mathrm{~min}$. In line with our earlier imagery study (van Overveld et al., 2009), parasympathetic activity of the cardiac system was indexed by the high frequency (HF) power band of HRV. To test further the complementary involvement of the digestive component of the ANS (e.g., van Overveld et al., 2009), we also monitored EMG activity of the digastricus muscle (that is responsible for swallowing) as an indirect measure of saliva production (Nederkoorn et al., 1999). As a relatively independent index of the sympathetic activation/withdrawal of the cardiac system, we measured the T-wave amplitude which is inversely related to (beta adrenergic) sympathetic activation (cf. Palomba et al., 2000). As an additional peripheral index of sympathetic activation we measured skin conductance level.

As a second aim, the present study investigated whether the strength of the autonomic responses varied as a function of individual differences in disgust propensity (defined as a general tendency to respond with the emotion of disgust to any given situation). Assuming that disgust propensity reflects differences in the disgust processing neural networks, one would expect increased disgust propensity to be associated with elevated subjective and physiological disgust responses. In line with this, previous work using a picture viewing paradigm indeed found a relationship between disgust propensity as indexed by the Disgust Scale (DS; Haidt et al., 1994) and subjective disgust (Stark et al., 2005). However, there was no relationship between DS scores and phys- iological indices. This may indicate that subjective disgust and physiological responses reflect independent phenomena (e.g., van Overveld et al., 2009). Yet, an alternative explanation could be that the picture paradigm lacks sufficient sensitivity to measure the most important physiological concomitants of disgust (e.g., parasympathetic responses). Thus, it would be important to complement these earlier findings with a study testing the relationship between DS and ANS activation during more prolonged stimulus exposure.

In addition, it could be questioned whether the DS is indeed the most appropriate index of disgust propensity in this context. The DS covers a limited set of very specific disgust elicitors. Hence only when there is a strong overlap between the exact content of the items of the DS and the actual stimuli that are used in an experiment, the DS may provide an accurate reflection of participants' disgust propensity (e.g., van Overveld et al., 2010). Since it has been shown that individuals' disgust propensity may be highly domain specific (e.g., de Jong and Merckelbach, 1998; Olatunji et al., 2008), this is a serious drawback for using the DS in the current context. In an attempt to overcome this potential drawback of the DS, a decontextualised measure of trait disgust has been developed, the so-called Disgust Propensity and Sensitivity Scale (DPSS; van Overveld et al., 2006). Independent of particular disgust elicitors, the DPSS asks people to rate how often certain statements such as "I find something disgusting", "I experience disgust", apply to them. The DPSS was recently revised and validated (DPSS-R, van Overveld et al., 2010; Fergus and Valentiner, 2009). Attesting to the relevance of using a decontextualised measure of disgust propensity, the DPSS-R was shown to have added predictive value for disgustinduced avoidance behavior over and above traditional indices of trait disgust (van Overveld et al., 2010). To test further the relationship between disgust propensity and disgust induced physiological responding, we therefore included both the DS and the DPSS-R in the present design.

Thus far, research on individual differences in trait disgust predominantly focused on people's general tendency to respond with the emotion of disgust to any given situation (disgust propensity). Therefore, the common trait disgust questionnaires such as the DS typically ask people to indicate to what extent they feel disgusted by certain stimuli. However, people may not only show relevant variation regarding their threshold for experiencing disgust (i.e., disgust propensity), but also regarding their appraisal of the experienced disgust responses (disgust sensitivity). That is, people not only vary in their tendency to experience the emotion of disgust more readily but also in their tendency to find the emotion of disgust unpleasant. By now there is considerable evidence that disgust propensity and disgust sensitivity represent separate constructs (e.g., van Overveld et al., 2006, 2010). Underlining the relevance of differentiating between both types of trait disgust, several studies showed that disgust propensity and disgust sensitivity are differentially related to symptoms of psychopathology. For example, in the context of post traumatic stress disorder (PTSD), disgust propensity was found to be associated with the probability of experiencing peritraumatic disgust, whereas disgust sensitivity moderated the predictive relationship between peritraumatic disgust and subsequent PTSD-symptom severity (Engelhard et al., 2011).

One explanation for the relatively negative appreciation of the experience of disgust in people with high disgust sensitivity could be that these people are characterized by relatively strong physiological responses towards disgusting stimuli. Therefore, as a third and final issue, we also tested whether higher scores on disgust sensitivity indeed coincide with stronger disgust-induced physiological responses. Insight in this relationship may not only be relevant in its own right, but may also provide relevant clues that may help improving our understanding of the relationship between disgust sensitivity and psychopathology. 
In sum, the major aims of the present study were to test (i) whether we could corroborate earlier findings suggesting that parasympathetic activation of the cardiac component of the ANS is involved in disgust, (ii) whether autonomic activation in response to a prolonged disgust eliciting stimulus is especially pronounced in individuals who are characterized by a high disgust propensity, and (iii) whether individuals with enhanced disgust sensitivity display relatively strong disgust induced physiological responses.

\section{Methods}

\subsection{Participants}

A large sample of students at the schools of Health Sciences, Medicine, and Psychology from Maastricht University completed the DPSS-R $(N=216)$ and indicated that they were willing to participate in a series of follow-up experiments. To ensure that scores across a broad range of the DPSS-R would be included in the present study, the initial research population $(N=216)$ was divided into deciles, and it was attempted to include an equal number of participants per decile. Eventually, sixty participants of this initial sample were approached and invited to the lab based on their scores of the DPSS-R. As female students are overrepresented at these faculties, the research population in the current study consists mostly of female participants (52 women; 86.7\%). The mean age of the research population was 21.58 years ( $S D=2.95$; range: $18-39$ years). The present study is part of a larger project on disgust, and the same individuals also participated in a study on disgust/induced avoidance behavior that has been reported in a separate manuscript (van Overveld et al., 2010).

\subsection{Instruments}

\subsubsection{Disgust Propensity and Sensitivity Scale-Revised (DPSS-R; van Overveld} et al., 2006)

This questionnaire measures the constructs of disgust propensity and sensitivity. Here, we used the recently validated shortened (12 item) version of the DPSS (Fergus and Valentiner, 2009). Participants read twelve propositions and indicated which response applied best to them on a scale from 1 (= 'never') to 5 (= 'always'; range: 12-60). Both the Propensity and the Sensitivity scales consisted of 6 items. Sample items of the Propensity Scale are: "I find something disgusting", "I experience disgust". Sample items of the Sensitivity Scale are: "I think feeling disgust is bad for me", "I'm frightened when I feel nauseous". Previous work showed that the DPSS-R was internally consistent with alpha coefficients of .78 (Propensity) and .79 (Sensitivity) (Fergus and Valentiner, 2009) and also in the present study the internal consistency was satisfactory (see Table 1).

\subsubsection{Disgust Scale (DS; Haidt et al., 1994)}

This study relied on the original 32-item DS. The DS covers eight types of disgust elicitors: body-envelope violations, animals, bodily products, hygiene, sex, food, death, and sympathetic magic. The DS consists of two parts: in the first part, participants indicated if they agreed with a series of 16 propositions using a dichotomous scoring format $(0=$ 'false', $1=$ 'true '), whilst in the second part, participants indicated how much they would be disgusted by 16 objects or situations on a three-points Likert-type scale $(0=$ 'not disgusting at all', .5 = 'slightly disgusting', 1 = 'very disgusting'). The total (sum) score of the DS (0-32) has been shown to be a reliable index for disgust propensity (alpha $=.84$; Haidt et al., 1994), and also in the present study the internal consistency was satisfactory (Table 1 ).

\subsubsection{Visual Analogue Scale (VAS)}

Participants rated on a $100 \mathrm{~mm}$ VAS their experienced level of disgust (e.g., how much disgust did you experience during this film?).

\subsection{Apparatus}

\subsubsection{Swallowing}

The amount of excreted saliva can be interpreted as an index of parasympathetic activity (Proctor and Carpenter, 2007). In the present study, saliva excretion was measured by continuous measurement of the EMG activity of the m. digastricus ("the swallow muscle") by using two $\mathrm{Ag} / \mathrm{AgCl}$ Beckman electrodes (diameter $2.5 \mathrm{~mm}$ ) filled with Spectra 360 electrode gel which were attached under the left jaw, lengthways along the anterior part of the musculus digastricus, at a distance of approximately $1.5 \mathrm{~cm}$ from each other. A reference electrode was placed on the left mastoid process (cf. Nederkoorn et al., 1999).

\subsubsection{Facial ElectroMyography (EMG)}

In addition to the m. digastricus, EMG activity was measured for two facial muscles, i.e., the $\mathrm{m}$. corrugator (as an index for general unpleasantness; see also Lang et al., 1993) and the $\mathrm{m}$. levator labii (as a unique index for the expression of disgust; see also Vrana, 2010). Measurements were obtained using two pairs of $\mathrm{Ag} / \mathrm{AgCl}$ Beckman electrodes (diameter $2.5 \mathrm{~mm}$ ) that were filled with Spectra 360 electrode gel.
Following recommendations by Fridlund and Cacioppo (1986), all electrodes were placed on the left side of the face.

\subsubsection{ElectroCardioGram (ECG)}

The ECG recordings were made by placing pre-gelled single-use disposable ECG surface electrodes (Ambu Bluesensor). Two electrodes were placed on the participant's lower ribs, and one on the sternum. The electrodes were connected directly with a Picker/Schwarzer Coupler (ED 14/12), with three unipolar leads. The ECG was monitored continuously and saved on the lab server for off-line processing. Respiration rate was not included in the present study.

\subsubsection{Skin conductance level (SCL)}

Using a Schwarzer EDA48 Amplifier, skin conductance was measured using the method of constant voltage $(.5 \mathrm{~V})$ as a further measure of sympathetic activity. Two $\mathrm{Ag} / \mathrm{AgCl}$ electrodes (diameter $7.0 \mathrm{~mm}$ ) were placed at the palmar side of the middle phalanges of the second and third fingers of the participant's non-dominant hand. The electrodes were filled with isotonic gel.

All ECG and EMG signals were fed through a Picker/Schwarzer Coupler(ED14/12) to a PXI data-acquisition system (PXI 4472; National Instruments) with a sample frequency of $1000 \mathrm{~Hz}$ with a time constant of $0.3 \mathrm{~s}$. A notch filter was used to eliminate any $50 \mathrm{~Hz}$ interference. Further, a low pass filter of $1.60 \mathrm{~Hz}$ and a high pass filter of $300 \mathrm{~Hz}$ were used. For skin conductance, signals were fed to the PXI-data acquisition system through a $500 \mathrm{~Hz}$ anti-aliasing filter. Data were stored on the lab server and processed off-line.

\subsection{Materials}

\subsubsection{Film clips}

Two 5-min video clips were presented: a neutral film (a documentary by Bert Haanstra on the making of glass; 1958), and a disgusting video clip consisting of edited excerpts from MTV's Jackass (2000), containing an egg-eating contest and a milk-drinking contest, during which participants vomit excessively. Both clips included relevant sounds, whereas parts of the documentary also included music The clips were presented on a 17 -in. computer screen, approximately $2 \mathrm{~m}$ from the individual. The clips were stored as avi files on the lab computer (Dell GX270, Pentium 4A, $3 \mathrm{GHz}$, Windows 2000). In a separate (female) sample $(N=15)$ it was verified whether indeed the neutral film was emotionally neutral and the disgust clips specifically elicited the emotion of disgust. Therefore, participants of this 'validation' sample were presented with the clips in the same order as during the experiment proper and rated on $100 \mathrm{~cm}$ Visual Analogue Scales to what extent the clips elicited disgust, fear, happiness, anger, and sadness $(0=$ not at all, $100=$ very much). For the neutral clip the mean scores were: $0.86(\mathrm{SD}=1.18), 1.26(\mathrm{SD}=2.01)$ $33.86(\mathrm{SD}=27.31), 1.33(\mathrm{SD}=2.02), 1.73(\mathrm{SD}=2.49)$, respectively. Thus although the documentary elicited some happiness, it was foremost not successful in eliciting strong emotions thereby supporting its validity as a neutral clip. For the disgust clip the mean scores were: $86.86(S D=16.61), 9.70(S D=11.95), 6.33(S D=8.66)$, $14.96(\mathrm{SD}=17.35), 1.80(\mathrm{SD}=2.62)$, respectively. Although participants indicated to experience some anger (and fear), the results clearly showed that specifically participants' disgust ratings were close to "very much" thereby sustaining the validity of the disgust clip.

\subsection{Procedure}

Upon arrival at the lab, participants were asked to complete a set of questionnaires containing the Dutch versions of the DPSS-R and DS. Next, they received a short introduction to the experiment and provided informed consent. Following this, electrodes were placed and the physiological signals were tested. First, participants viewed the neutral film. Shortly after completing the VASs regarding the neutral film clip, the disgusting film clip was started by the experimenter. Following viewing the disgusting clip participants completed again a series of VASs regarding the film. At the end of the experiment participants were debriefed and received ten euros for their participation.

\subsection{Data reduction and analysis}

For the EMG data, specifically designed software was used to digitally rectify and integrate the signals with a time constant of $0.3 \mathrm{~s}$. Following this, a root transformation was applied to normalize the skewed distribution of the EMG data. Then, mean EMG activity was calculated for the $\mathrm{m}$. corrugator, $\mathrm{m}$. levator, and $\mathrm{m}$. digastricus. For HR, specifically designed software was used to determine the R-tops in the ECG data. Using the interval between these successive R-tops, the HR was then calculated.

HRV was defined as the variability of the intervals between successive heart beats (R-tops in the ECG). Generally, three components can be established: very low frequency (VLF: $0.04<\mathrm{Hz}$ ), low frequency $(0.04-0.15 \mathrm{~Hz}$ ), and high frequency (HF: $0.15-.40 \mathrm{~Hz}$ ). As the HF component is under the influence of the nervus vagus, the power in this band is assumed to indicate parasympathetic activity (Task Force of the European Society of Cardiology et al., 1996). Consequently, only the power in the high frequency band was calculated in this experiment. To calculate the power in the HF-band, the CARSPAN software package (IEC ProGamma, Groningen, 
Table 1

Descriptive statistics for indices of disgust propensity (DPSS-RP, DS) and disgust sensitivity (DPSS-RS)

\begin{tabular}{lllcl}
\hline Indices & Means $(N=60)$ & SD & Range $(\min -\max )$ & $\alpha$ \\
\hline DPSS-RP & 15.98 & 2.61 & $10-21(6-30)$ & .66 \\
DPSS-RS & 11.69 & 3.49 & $7-20(6-30)$ & .75 \\
DS total & 16.37 & 2.40 & $12-23(0-32)$ & .82 \\
\hline
\end{tabular}

Abbreviations: DPSS-RP: Disgust Propensity and Sensitivity Scale-Revised Propensity, DPSS-RS: Disgust Propensity and Sensitivity Scale-Revised Sensitivity, and DS: Disgust Scale.

the Netherlands) was used, which conducted a spectral analysis on the Inter-Beat Intervals according to a discrete Fourier transform algorithm. As suggested by the Task Force of the European Society of Cardiology and the North American Society of Pacing Electrophysiology (1996), normalized units were then calculated for the power in the HF-band for each film using the following formula: (HF power/(total power - VLF) $\times 100$. Respiration rate was not taken into account in the present study (cf. van Overveld et al., 2009).

Next, the T-wave amplitude was obtained by calculating the difference in $\mu \mathrm{V}$ between the maximum value included in a $100-300 \mathrm{~ms}$ window following the Rwave and the mean value of the 40 -ms isoelectric line between P-wave and Qwave (Rau, 1991). Following this, the mean T-wave amplitude during the films was calculated as an indicator for withdrawal of sympathetic activity (Kline et al., 1998). It should be acknowledged, however, that the amplitude measurement might have been affected by some distortion because the time constant we used $(0.3 \mathrm{~s})$ was relatively short. For skin conductance level, the mean activity during the films was calculated.

In line with previous research on the cardiovascular indicators of disgust (e.g., Rohrmann and Hopp, 2008), a comparison between the control measurement (neutral clip) and the disgust inducing clip was used to determine disgust-related physiological responsivity. Thus using the neutral film as a "vanilla baseline" (Jennings et al., 1992), we first tested the contrast between the neutral and disgust condition for all parameters using a series of paired $t$ tests (cf. Rohrmann and Hopp, 2008). Because of a priori directional predictions regarding the pattern of responding including the subjective experience of disgust (VAS), saliva production (EMG m. digastricus), expression of disgust and negative affect (EMG $\mathrm{m}$. levator and $\mathrm{m}$. corrugator), increased parasympathetic influence on cardiac activity (power in $\mathrm{HF}$ band), and increase in sympathetic activity (as indexed by SCL), these contrasts were tested one-tailed. Because on the basis of previous research and theoretical considerations no unambiguous predictions could be derived for HR and T-wave amplitude, these contrasts were tested two-tailed. To protect against Type 1 error inflation from multiple tests, alpha was set at .025 for the latter comparisons. For all contrasts the partial eta squared $\left(\eta_{p}^{2}\right)$ is reported as an index of effect size (small: 0.01, medium: 0.06, and large effect: 0.14; Cohen, 1977).

Subsequently, we computed a series of bivariate Pearson's $p-m$ correlations to test whether participants' physiological reactivity (mean physiological activity during disgust-film minus mean activity during neutral film) and subjective state disgust (mean VAS-scores during disgust-film minus VAS-scores during neutral film) varied as a function of their trait disgust propensity (DPSS-RP, DS) and/or disgust sensitivity (DPSS-RS)

\section{Results}

\subsection{Descriptives}

Table 1 presents the means, standard deviations, range as well as Cronbach's alpha for the trait-disgust questionnaires.

\subsection{Subjective and psychophysiological responding during disgust video clip}

Table 2 shows the differences in subjective ratings and physiological activity between the neutral and the disgust video clip. ${ }^{1}$ In the final column we reported the effect size as indexed by $\eta_{p}^{2}$. Attesting to the validity of the present manipulation, the levels of state disgust (VASs) were substantially increased during the disgust film compared to the neutral film.

\footnotetext{
${ }^{1}$ To control for the potential influence of gender imbalance in this study, we repeated these analyses without the 8 male participants. The outcome of these additional analyses mimicked the original results, and effects sizes remained very similar.
}

As expected, a significant increase in activity was observed in the $\mathrm{m}$. digastricus and the $\mathrm{m}$. levator labii. Unexpectedly, the activity of the corrugator muscle that is usually considered to reflect negative affect decreased rather than increased. Most important for the present context, there was evidence for increased parasympathetic influence on cardiac activity as indexed by the power in the HF band. In addition, HR increased and there was a nonsignificant tendency $(p=04)$ for a decreased T wave amplitude. Both the increase in HR and the decrease of T wave amplitude indicate that during the disgust clip there was also increased sympathetic influence on cardiac activity compared to the neutral condition. In line with this and consistent with previous research, SCL was significantly higher during the disgust clip than during the neutral control film.

\subsection{Correlations between state and trait disgust and physiological reactivity}

Only trait disgust propensity as indexed by the DS correlated significantly with the subjective index of state disgust $(r=.55, p<.01)$. Neither the subjective disgust that was elicited during the disgust clip, nor participants' trait disgust propensity as indexed by the DPSS-R or DS, or participants' trait disgust sensitivity as indexed by the DPSS-R, were associated with the strength of participants disgust-induced physiological reactivity $(-.23<$ rs $<.25)$. Thus, it appears that physiological reactivity and subjective experience present two dissociated phenomena.

\section{Discussion}

The major aim of the present study was to investigate whether parasympathetic activation of the cardiac system is an integral part of disgust-induced physiological responsivity. The main findings can be summarized as follows: (a) prolonged exposure to a disgust-relevant film elicited a physiological response pattern characterized by increased parasympathetic activity of both the cardiac and the digestive components of the ANS, together with increased sympathetic activation of the cardiac system, (b) disgust-induced responses of the ANS were independent of subjective disgust and were not moderated by individuals' habitual disgust propensity, and (c) people with relatively strong disgust sensitivity did not show enhanced disgust-induced physiological responses.

Using a prolonged passive film viewing approach, the present study provided further support for the hypothesis that parasympathetic responses are part of the psychophysiology of disgust (e.g., Levenson, 1992). Consistent with previous work using disgust imagery rather than passive film viewing (van Overveld et al., 2009), the enhanced muscular activity of the m. digastricus suggests that the emotion of disgust is accompanied by enhanced saliva production. The saliva response likely indicates an increase in parasympathetic activity (Proctor and Carpenter, 2007). In addition, we found evidence for disgust induced parasympathetic responses of the cardiac ANS component. More specifically, the results showed increased heart rate variability (HRV) as indexed by power in the HF band during the disgust film. This pattern of findings fits nicely with previous research using a similar type of disgust elicitor (Rohrmann and Hopp, 2008). Together the available evidence converges to the conclusion that parasympathetic activation of both the digestive and the cardiac components of the ANS are part of the disgust response. The present results are also in line with the suggestion that the failure to find evidence for enhanced cardiac PNS in our previous study (van Overveld et al., 2009) might have been due to the task demands associated with the imagery methodology.

Consistent with previous research using a similar passive film viewing paradigm (Rohrmann and Hopp, 2008), we also found evi- 
Table 2

Physiological and subjective reactivity during neutral film and disgusting film.

\begin{tabular}{|c|c|c|c|c|}
\hline Parameters & Neutral film & Disgust film & $t(59)$ & $\eta_{p}^{2}$ \\
\hline Subjective disgust $(0-100)$ & $1.63(5.51)$ & $49.85(30.21)$ & $-12.33^{*}$ & .721 \\
\hline Digastricus muscle $(\mu \mathrm{V})$ & $7.25(3.91)$ & $7.61(4.30)$ & $-2.40^{*}$ & .088 \\
\hline \multicolumn{5}{|l|}{ Facial EMG } \\
\hline $\operatorname{Corr}(\mu \mathrm{V})$ & $8.11(4.50)$ & $7.58(4.29)$ & $1.72^{*}$ & .048 \\
\hline $\operatorname{Lev}(\mu \mathrm{V})$ & $6.23(3.18)$ & $8.51(5.46)$ & $-5.21^{*}$ & .315 \\
\hline \multicolumn{5}{|l|}{ Cardic parameters } \\
\hline HF (nu) & $56.21(49.29)$ & $81.45(79.46)$ & $-1.92^{*}$ & .060 \\
\hline $\mathrm{HR}$ (bpm) & $78.45(11.14)$ & $80.21(12.20)$ & $2.43^{\#}$ & .094 \\
\hline TWA $(\mu V)$ & $275.18(134.53)$ & $267.84(128.48)$ & $2.14^{\mathrm{a}}$ & .074 \\
\hline $\operatorname{SCL}(\mu \mathrm{S})$ & $1.50(.86)$ & $2.01(1.01)$ & $-8.23^{*}$ & .534 \\
\hline Valid N & & & 60 & \\
\hline
\end{tabular}

*Statistically significant ( $p<.05$, one-tailed); ${ }^{*}(p<.025$, two tailed $) ;{ }^{a}(p>.025$, two-tailed $)$.

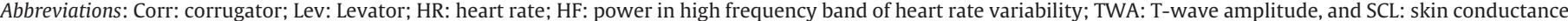
level.

dence for sympathic activation as part of the disgust response. That is, the increase in HR despite the concurrent increase in parasympathetic activation seems to imply that the HR increase can be best explained by a parallel increase of sympathetic influence on the cardiac system. Consistent with this, the present tendency for a decreased T-wave amplitude during the disgust clip also points to increased (beta adrenergic) sympathetic activation (Kline et al., 1998). As a further indication of increased sympathetic activation during disgust, participants' skin conductance level was substantially higher during the disgust than during the neutral film clip. Thus the data seem to indicate that both parasympathetic and sympathetic activation are involved in disgust.

No evidence emerged to support the notion that trait disgust propensity as indexed by the DS or DPSS would be associated with enhanced physiological responsivity. Supporting the validity of the DS as an index of disgust propensity, the results showed that people with relatively high scores on the DS, also indicated to experience relatively intense disgust during the film. However, in line with previous research using a picture viewing paradigm (Stark et al., 2005), there was no meaningful relationship between DS scores and any of the physiological indices of disgust. The absence of a relationship between disgust propensity and physiological responding was not restricted to the DS. Also, the scores on the decontextualised disgust propensity scale (DPSS-RP) were largely independent of the physiological concomitants of disgust. All in all, the results seem to indicate that enhanced subjective disgust propensity and enhanced physiological responding to disgust reflect unrelated characteristics. The conclusion that subjective and physiological indices of disgust propensity represent largely independent phenomena is consistent with previous work showing marked gender differences in self reported disgust, whereas physiological disgust responses were only marginally moderated by gender (Rohrmann et al., 2008).

In a similar vein, the present findings provided no evidence to support the hypothesis that a relatively negative appreciation of the experience of disgust (i.e., enhanced disgust sensitivity) can be traced back to enhanced physiological responsivity. As was found for trait disgust propensity, trait disgust sensitivity also appeared largely independent of people's physiological response pattern. Accordingly, the present findings do not support the notion that the relationship between enhanced disgust sensitivity and psychopathological symptoms (e.g., emetophobia; van Overveld et al., 2008) might be due to exaggerated disgust-induced autonomic responsivity. Probably, the role of enhanced disgust sensitivity in psychopathology can be best explained by dysfunctional disgust appraisals rather than enhanced disgust responding (cf. Teachman, 2006; Engelhard et al., 2011).

Previous research, using threatening rather than disgusting film materials (e.g., materials from the Hitcher movie depicting a boy threatened by a man armed with a knife) showed a different pattern of autonomic responding towards prolonged passive film viewing. Although threatening film clips also elicited sympathetic responses as indexed by reduced T-wave amplitude and enhanced SCL, HR typically increased without evidence for enhanced parasympathetic activation of the cardiac system (e.g., Palomba et al., 2000). Thus whereas threat-induced fear tend to be specifically accompanied by enhanced sympathetic activation that support quick (fight/flight) responses, disgust-induced autonomic responsivity seems characterized by a concurrent activation of both the sympathetic and parasympathetic branches of the ANS.

Starting from the hypothesis that core disgust originates from a withdrawal response regarding the oral incorporation of potential contaminants (Rozin et al., 1999), it would make sense that core disgust typically activates digestive components of the ANS (e.g., saliva production, tendency to vomit). This type of gastrointestinal regulation is typically controlled by the parasympathetic nervous system (Guyton and Hall, 2006), and increased parasympathetic activation may well express itself also in enhanced vagal tone thereby influencing the cardiac system (Levenson, 1992). The concurrent increase in sympathetic activation may support the metabolic requirements of disgust-induced avoidance and escape behaviors, similar to the sympathetic support of the fight/flight responses in the context of fear-eliciting situations.

Some comments are in order regarding the limitations of the present study following from the methodology of the current experiment. First, we did not experimentally control for respiratory effects on people's cardiac responding. We preferred spontaneous breathing over controlled breathing because we were afraid that paced breathing would prevent people from getting absorbed in the film clips and might also directly influence experienced affect (e.g., Zautra et al., 2010), thereby detracting from the efficacy of the current emotion-induction (see also Berntson et al., 1997). Moreover, it would have hampered the direct comparison of the present study with previous research, because these studies also tested cardiac responses towards disgust in the context of spontaneous breathing. However, since both frequency and depth of respiration can influence HRV (e.g., Grossman et al., 1991), it cannot be ruled out that the relatively strong HF power during the present disgust film condition (partly) reflected differential respiratory effects. Since we did not assess respiratory parameters, the available data do not allow to evaluate whether indeed the HRV effects might be attributable to respiratory effects such as a lowered respiratory rate during the disgust film.

In addition, it should be acknowledged that we only assessed the intensity of disgust that was elicited by the present films. Although both the facial EMG of the levator muscle and the subjective ratings indicated that our film elicited considerable levels of disgust, it cannot be ruled out that also other emotions such as fear, anger, or happiness were elicited by the current film. However, the findings 
of the validation study indicating that the disgust clips specifically elicited feelings of disgust renders this not very likely.

The present design only included neutral and disgusting materials. Therefore, we could not directly compare the physiological reactivity in response to disgusting with the reactivity in response to threatening film materials. To arrive at more final conclusions regarding the specificity of the present response pattern for disgust it would be critical to include clips eliciting other emotions such as fear, sadness, and happiness in addition to the present disgust clip in a single experiment. Additionally, it should be noted that we used the neutral clip as a "vanilla" baseline. The absence of pre-clip baseline assessments might have obscured relevant differences between the responsivity to both types of clips. This might also have reduced the sensitivity of the design to find a relationship between subjective and physiological disgust responses. It would therefore be important for future research to include both neutral clip and pre-clip rest baselines. It should be further acknowledged that we used a fixed order and always started with the neutral control clip. Although this has clear advantages in terms of enhancing the sensitivity of the design to individual differences in trait disgust, this procedure also has the drawback that it reduces the sensitivity of the design for slow physiological responses such as skin conductance level.

Finally, the present study was restricted to disgust elicitors from the domain of core disgust. Although our previous imagery study (van Overveld et al., 2009) provided no evidence for a domainspecific physiological response pattern, it cannot be ruled out that in the context of the current passive viewing approach differential response patterns may occur. As a next step, it may thus be relevant to see whether also other types of disgust (i.e., animal-reminder, interpersonal, and moral; Rozin et al., 1999) elicit a similar concurrent sympathetic/parasympathetic response pattern.

In conclusion, the present study yielded further support for the hypothesis that activation of the parasympathetic nervous system is involved in disgust. The apparent divergence of this response pattern from the pattern of ANS activation that has been reported for other negative emotions such as fear supports the view that there are ANS differences among emotions (e.g., Levenson, 1992). The absence of a relationship between subjective indices of trait/state disgust and physiological responding, indicates that both types of responses reflect independent phenomena.

\section{Acknowledgements}

The authors wish to express their gratitude to Joëlle Janssen for her efforts in the process of data acquisition of the actual experiment and to Jisca Kuiper and Charmaine Borg for taking care of the validation study.

\section{References}

Berntson, G.G., Bigger Jr., J.T., Eckberg, D.L., Grossman, P., Kaufmann, P.G., Malik, M., Nagaraja, H.N., Porges, S.W., Saul, J.P., Stone, P.H., van der Molen, M.W., 1997. Heart rate variability: origins, methods, and interpretive caveats. Psychophysiology 34, 623-648.

Cohen, J., 1977. Statistical Power Analysis for the Behavioral Sciences, rev. edn. Lawrence Erlbaum Associates, Inc., Hillsdale, NJ, England.

Davey, G.C.L., 1994. Self-reported fears to common indigenous animals in an adult UK population: the role of disgust sensitivity. British Journal of Psychology 85 541-544.

de Jong, P.J., Merckelbach, H., 1998. Blood-injection-injury phobia and fear of spiders: domain specific individual differences in disgust sensitivity. Personality and Individual Differences 24, 153-158.

de Jong, P.J, Muris, P., 2002. Spider phobia: interaction of disgust and perceived likelihood of involuntary physical contact. Journal of Anxiety Disorders 16, 51-65.

Ekman, P., Levenson, R.W., Friesen, W.V., 1983. Autonomic nervous system activity distinguishes among emotions. Science 221, 1208-1210.

Engelhard, I., Olatunji, B., de Jong, P.J., 2011. Disgust and the development of posttraumatic stress among soldiers deployed to Afghanistan. Journal of Anxiety Disorders 25, 58-63.
Fergus, T.A., Valentiner, D.P., 2009. The Disgust Propensity and Sensitivity ScaleRevised: an examination of a reduced-item version. Journal of Anxiety Disorders 23, 703-710.

Fridlund, A.J., Cacioppo, J.T., 1986. Guidelines for human electromyographic research. Psychophysiology 23, 567-598.

Grossman, P., Karemaker, J., Wieling, W., 1991. Prediction of tonic parasympathetic cardiac control using respiratory sinus arrhythmia: the need for respiratory control. Psychophysiology 28, 201-216.

Guyton, A.C., Hall, J.E., 2006. Textbook of Medical Physiology, 11th ed. Elsevier Saunders, Philadelphia.

Haanstra, B., 1958. Glass. Go Pictures, Netherlands.

Haidt, J., McCauley, C., Rozin, P., 1994. Individual differences in sensitivity to disgust: a scale sampling seven domains of disgust elicitors. Personality and Individual Differences 16, 701-713.

Jackass, 2000. Dickhouse Productions, USA

Jennings, J.R., Kamarck, T., Stewart, C., Eddy, M., Johnson, P., 1992. Alternate cardiovascular baseline assessment techniques: vanilla or resting baseline. Psychophysiology 29, 742-750.

Kline, K.P., Ginsburg, G.P., Johnston, J.R., 1998. T-wave amplitude: relationships to phasic RSA and heart period changes. International Journal of Psychophysiology 29, 291-301.

Lang, P.J., Greenwald, M.K., Bradley, M.M., Hamm, A.O., 1993. Looking at pictures: affective, facial, visceral, and behavioural reactions. Psychophysiology 30, 261-273.

Levenson, R.W., 1992. Autonomic nervous system differences among emotions. Psychological Science 3, 23-27.

Nederkoorn, C., Smulders, F.T.Y., Jansen, A., 1999. Recording of swallowing events using electromyography as a non-invasive measurement of salivation. Appetite 3, 361-369.

Olatunji, B.O., Haidt, J., McKay, D., David, B., 2008. Core, animal reminder, and contamination disgust: three kinds of disgust with distinct personality, behavioral, physiological, and clinical correlates. Journal of Research in Personality 42, 1243-1259.

Olatunji, B., McKay, D., 2010. Disgust and its Disorders: Theory, Assessment and Treatment. American Psychological Association, Washington, DC, pp. 123-143.

Palomba, D., Sarlo, M., Angrilli, A., Mini, A., Stegagno, L., 2000. Cardiac responses associated with affective processing of unpleasant film stimuli. International Journal of Psychophysiology 36, 45-57.

Proctor, G.B., Carpenter, G.H., 2007. Regulation of salivary gland function by autonomic nerves. Autonomic Neuroscience: Basis and Clinical 133, 3-18.

Rau, H., 1991. Responses of the T-wave amplitude as a function of active and passive tasks and beta-adrenergic blockade. Psychophysiology 28, 231-239.

Rohrmann, S., Hopp, H., 2008. Cardiovascular indicators of disgust. International Journal of Psychophysiology 68, 201-208.

Rohrmann, S., Hopp, H., Quirin, M., 2008. Gender differences in psychophysiological responses to disgust. Journal of Psychophysiology 22, 65-75.

Rozin, P., Haidt, J., McCauley, C.R., 1999. Disgust: the body and soul emotion. In: Dalgleish, T., Power, M. (Eds.), Handbook of Cognition and Emotion. John Wiley \& Sons Ltd., New York.

Sarlo, M., Buodo, G., Munafo, M., Stegagno, L., Palomba, 2008. Cardiovascular dynamics in blood phobia: evidence for a key role of sympathetic activity in vulnerability to syncope. Psychophysiology 45, 1038-1045.

Stark, R., Walter, B., Schienle, A., Vaitl, D., 2005. Psychophysiological correlates of disgust and disgust sensitivity. Journal of Psychophysiology 19, 50-60.

Task Force of the European Society of Cardiology and the North American Society of Pacing and Electrophysiology, 1996. Heart rate variability: standards of measurement, physiological interpretation and clinical use. Circulation 93 , 1043-1065.

Teachman, B.A., 2006. Pathological disgust: in the thoughts, not the eye, of the beholder. Anxiety, Stress \& Coping: An International Journal 19, 335-351.

Vaitl, D., Schienle, A., Stark, R., 2005. Neurobiology of fear and disgust. International Journal of Psychophysiology 57, 1-4.

van Overveld, W.J.M., de Jong, P.J., Peters, M.L., Cavanagh, K., Davey, G.C.L., 2006. Disgust propensity and disgust sensitivity: separate constructs that are differentially related to specific fears. Personality and Individual Differences 41 , 1241-1252.

van Overveld, W.J.M, de Jong, P.J., Peters, M.L., 2009. Digestive and cardiovascular responses to core and animal-reminder disgust. Biological Psychology 80, 149-157.

van Overveld, W.J.M., de Jong, P.J., Peters, M.L., 2010. The Disgust Propensity and Sensitivity Scale-Revised: its predictive value for avoidance behavior. Personality and Individual Differences 49, 706-711.

van Overveld, M., de Jong, P.J., Peters, M.L., van Hout, W.J.P.J., Bouman, T.K., 2008. An internet-based study on the relation between disgust sensitivity and emetophobia. Journal of Anxiety Disorders 22, 524-531.

Vrana, S.R., 1993. The psychophysiology of disgust: differentiating negative emotional contexts with facial EMG. Psychophysiology 30, 279286.

Vrana, S.R. 2010. The psychophysiology of disgust: motivation, action and autonomic support. In: Olatunji, B., McKay, D. (Eds.), Disgust and its Disorders: Theory, Assessment, and Treatment. American Psychological Association, Washington, DC, pp. 123-143.

Zautra, A.J., Fasman, R., Davis, M.C., Craig, A.D., 2010. The effects of slow breathing on affective responses to pain stimuli: an experimental study. Pain 149, 12-18. 